\title{
Mandioca, macaxeira e aipim na Região Sudeste do Brasil: distribuição diatópica e comentários geolinguísticos dos informantes
}

\author{
Mandioca, macaxeira and aipim in brazilian Southeast Region: diatopical \\ distribution and geolinguistic comments from respondents \\ Valter Pereira ROMANO* \\ Universidade Federal de Santa Catarina (UFSC) \\ João Fernando CÁ ${ }^{* *}$ \\ Universidade Federal de Lavras (UFLA)
}

\begin{abstract}
RESUMO: Este texto apresenta um estudo acerca da variação lexical na Região Sudeste do Brasil com vistas a discutir a distribuição diatópica dos designativos que recobrem o conceito para a "raiz branca por dentro, coberta por uma casca marrom, que se cozinha para comer", questão 50 do Questionário Semântico-Lexical do Projeto Atlas linguístico do Brasil. Os dados são apresentados em gráficos, tabelas e cartas linguísticas perfazendo um total de 316 informantes distribuídos entre 79 municípios (37 paulistas, 23 mineiros, 17 fluminenses e 5 capixabas). O estudo traz comentários geolinguísticos dos informantes e evidencia a consciência deles no que tange à variação diatópica do Português Brasileiro. A distribuição dos itens revela duas áreas lexicais no território, uma de ocorrência de aipim e outra da variante mandioca, que permitem o traçado de linhas de isoléxicas e heteroléxicas na área investigada.
\end{abstract}

PALAVRAS-CHAVE: Variação lexical. Geolinguística. Região Sudeste. Projeto ALiB.

ABSTRACT: This paper presents a study on the lexical variation in Brazilian southeast region in order to discuss the designatives diatopical distribution that covers the concept for "white root inside, covered with a brown bark, which is cooked to eat", question 50 of the Semantic-Lexical Questionnaire of Brazilian Linguistic Atlas Project. Data are presented in graphs, tables and linguistic charts, totalizing 316 respondents distributed among 79 counties (37 from São Paulo state, 23 from Minas Gerais state, 17 from Rio de Janeiro state and 5 from Espírito Santo state). This study provides geolinguistic comments from respondents and highlights their awareness of Brazilian Portuguese diatopic variation. Items distribution reveals two lexical areas in the territory, one from aipim event and another from mandioca variant, which allows drawing isolexic and heterolexic lines in the investigated area.

KEY-WORDS: Lexical variation. Geolinguistic. Southeast Region. ALiB Project.

\footnotetext{
* Doutor em Estudos da Linguagem pela Universidade Estadual de Londrina (2015). Mestre em Estudos da Linguagem (2012) e Graduado em Letras Vernáculas (2009) nesta mesma instituição. Professor adjunto em regime de dedicação exclusiva no Departamento de Língua e Literatura Vernáculas da Universidade Federal de Santa Catarina (UFSC). Pesquisador do Projeto Atlas Linguístico do Brasil. Desenvolve suas pesquisas na área de Dialetologia, Sociolinguística, Geolinguística. E-mail: valter.romano@hotmail.com

${ }^{* *}$ Mestrando em Letras pela Universidade Federal de Lavras (UFLA). E-mail: joavi2012@ @otmail.com
} 


\section{Introdução}

A consciência da variação linguística perpassa o conhecimento dos falantes de forma quase intuitiva e revela características que os definem como pertencentes ou não a um grupo, conforme estudos sociolinguísticos e dialetológicos têm comprovado, como o de Aguilera (2008), o de Freitag et al. (2015) entre outros. A variação diatópica, ou espacial, sobretudo a de natureza lexical, desperta no indivíduo curiosidade. Assim, as variantes lexicais são atribuídas de forma genérica ao modo de falar de determinado grupo considerando a área geográfica em que reside. Por exemplo, frases do tipo: "jerimum é a forma como os nordestinos chamam a abóbora", "guri é o modo como os gaúchos denominam os meninos", "os cariocas chamam de biscoito aquilo que os paulistas conhecem como bolacha" etc. são ouvidas comumente em se tratando da diversidade linguística de um país de dimensões continentais como o Brasil.

Sendo o léxico o conjunto de palavras criadas e assimiladas pelo ser humano ao longo do tempo (BIDERMAN, 1992), de acordo com Isquerdo (2007, p. 533), ele representa "um aspecto diferenciador no que se refere à variação linguística, pois, além de evidenciar diferenças de uma região para outra, demonstra também a consequente mobilidade dessas diferenças de um espaço para outro". Desse modo, "verificar as especificidades lexicais de cada área geográfica é uma tarefa desafiadora, dada a dinamicidade da língua e a disseminação de variantes” (ROMANO, 2015, p. 21).

As longas distâncias e a formação sociocultural favorecem essa diversidade lexical de cunho diatópico do Português Brasileiro (PB), que é uma marca característica dessa língua plural e polarizada (LUCCHESI, 2006). Porém, de fato, será que um paraibano, sem escolaridade ou mesmo escolarizado, saberia dizer o que é um arroio ou uma sanga? E um piá paranaense conseguiria identificar o marraio e a bila? Obviamente, preferiria brincar de burquinha ou soltar pandorga, mas jamais chuparia caramelo como o fazem os guris de Cuiabá, e muito menos chuparia bombom como os meninos do Pará. Para um paulista, talvez, seja difícil associar musse à geleia, enquanto que, para o catarinense seria uma tarefa mais fácil, principalmente no litoral leste. Já o gaúcho insiste em dizer que guris adoram a chimia, vivem comendo bergamotas e correndo atrás das cigarras, enquanto paulistas observam os moleques nos faróis da grande São Paulo e os do interior vivem caçando as libélulas ou seriam as pitas/os? A mimosa de Curitiba é tanja em São Luiz/MA, a tangerina de Manaus, a laranja-cravo de João Pessoa. Estes breves exemplos, longe de serem fatos curiosos sobre a variação 
linguística do $\mathrm{PB}$, são uma realidade comprovada cientificamente por trabalhos empíricos desenvolvidos no âmbito dos estudos geolinguísticos há pelo menos 57 anos, remontando o ano de 1963, ocasião de publicação da pioneira obra de Rossi e suas colaboradoras (1963), o Atlas Prévio dos Falares Baianos (ROSSI et al. 1963).

O trabalho de Rossi et al. (1963), juntamente com quatro outras importantes obras, a de Ribeiro et al. (1977), Ferreira et al. (1987), Aragão e Bezerra de Menezes (1984) e Aguilera (1994), deram as bases sólidas para a instauração de uma área de interesse nos estudos linguísticos no território brasileiro, a Geolinguística, e contribuíram decisivamente para o início das atividades do Projeto Atlas Linguístico do Brasil, doravante ALiB.

Este texto traz reflexões acerca da variação lexical na Região Sudeste do Brasil, pautando-se em dados do Projeto ALiB com vistas a discutir a distribuição diatópica dos designativos que recobrem o conceito para a "raiz branca por dentro, coberta por uma casca marrom, que se cozinha para comer", questão 50 do Questionário SemânticoLexical (COMITE NACIONAL, 2001). Apresentam-se também comentários dos informantes que revelam a consciência da variação diatópica no âmbito do léxico, por vezes, generalizada, mas que em alguns casos podem ser ratificados/retificados pelos inúmeros atlas linguísticos que se tem notícia, conforme se encontra em Romano (2013) e Romano (no prelo).

Este artigo é o recorte de um estudo maior sobre os designativos no corpus do ALiB para as questões 50 (aipim/mandioca) e 51 (mandioca brava) do QSL, que está em andamento com dados de outras regiões administrativas. Justifica-se pela necessidade de trabalhos prévios com o corpus do Projeto para contribuir com a discussão de uma cartografia linguística exequível em rede de pontos densa, como a Região Sudeste.

O texto está organizado em três seções, além dessa introdução e das considerações finais. A próxima seção apresenta o ALiB e menciona-se alguns trabalhos desenvolvidos sobre o léxico com o corpus experimental do interior. A seção 2 traz os materiais e métodos do presente estudo. Na seção 3, são discutidos os resultados, seguindo-se as considerações e as referências mencionadas no texto. 


\section{O Projeto ALiB}

Iniciado no ano de 1996, mas preconizado na década de 1950 por eminentes filólogos e linguistas como Celso Cunha e Serafim da Silva Neto (1957), inclusive com o respaldo de um Decreto governamental de $1952^{1}$, e sistematizado por Antenor Nascentes (1958), o Projeto ALiB, atualmente, é uma realidade, resultante da iniciativa de pesquisadores que se colocaram a campo, constituindo equipes em todo o território nacional para a documentação da língua falada no Brasil em pequenas, médias e grandes cidades $^{2}$.

Esse projeto interinstitucional, sediado nacionalmente na Universidade Federal da Bahia, atualmente sob a presidência da Dra ${ }^{a}$. Jacyra Andrade Mota, e coordenado por um Comitê Nacional, envolve pelo menos nove universidades brasileiras. Tem como objetivo principal descrever a variante brasileira da língua portuguesa nos níveis fonético-fonológico, semântico-lexical, morfossintático e pragmático-discursivo sob a perspectiva da Dialetologia pluridimensional (THUN, 1998).

Para tanto, a equipe do Projeto, no período que compreende os anos de 2001 a $2013^{3}$, aplicou questionários a brasileiros de duas faixas etárias (18-30 e 50-65 anos), de ambos os sexos, em todo o território nacional (interior e capital). Em cada localidade do interior entrevistaram-se quatro informantes de nível fundamental e, nas capitais, somam-se mais quatro de nível superior. No total, o corpus do Projeto perfaz o registro da fala de 1100 brasileiros. Atualmente, a coleta de dados nos 250 pontos linguísticos está concluída e o Projeto entra em uma nova fase de sua elaboração, a transcrição e revisão desses dados para posterior armazenamento em um banco de dados geral ${ }^{4}$.

Também se tem desenvolvido pesquisas com o corpus do ALiB a nível de graduação e pós-graduação orientadas pelos diretores científicos. Esses trabalhos prévios de tratamento dos dados, sobretudo, da rede de pontos do interior, têm servido de base para discussões acerca do grande volume de dados coletados. No âmbito do

\footnotetext{
1 Disponível em: < http://www2.camara.gov.br/legin/fed/decret/1950-1959/decreto-30643-20-marco1952-339719-publicacaooriginal-1-pe.html $\geq$

${ }^{2}$ Sobre a história do ALiB, consulte Cardoso (2014a) . Detalhes do Projeto podem ser obtidos em: https://alib.ufba.br/ .

${ }^{3} \mathrm{O}$ primeiro inquérito para a constituição do corpus do ALiB foi realizado no dia 01 jun. de 2001 pela Equipe da Regional Paraná, em Quirinópolis-GO (ponto 126) e o último inquérito foi realizado no dia 18 de set. 2013 pela Equipe da Bahia em Limoeiro-PE e Olinda-PE (pontos 64 e 65).

${ }^{4}$ Foram publicados em 2014 os dois primeiros volumes Cardoso et al (2014a, b;). Os próximos volumes estão em elaboração. Mais informações acesse: https://alib.ufba.br/.
} 
léxico, encontram-se trabalhos que tem contribuído para discussão da divisão dialetal estabelecida por Nascentes (1953), como os de: Marins (2012), Ribeiro (2012), Razky (2013), Portilho (2013), Romano e Aguilera (2014), Romano e Seabra (2014a, 2014b), Romano (2015), D’Anunciação (2016), Santos (2016), Romano e Seabra (2017), Yida (2019), Chofard (2019) . Este texto vem somar a esses e outros trabalhos em desenvolvimento pela equipe de pesquisadores do Projeto.

\section{Materiais e Métodos}

O corpus analisado neste artigo integra o banco de dados inédito do Projeto $\mathrm{ALiB}$ e se refere à fala de 316 informantes divididos, equitativamente, segundo sexo e a faixa etária supramencionada de 79 municípios da Região Sudeste ${ }^{5}$. Assim, os informantes são identificados de 1 a 4 , sendo 1 e 2 (faixa I) e 3 e 4 (faixa II), os números 1 e 3 (homens) e 2 e 4 (mulheres).

Os dados foram levantados a partir da consulta aos arquivos de transcrição e da outiva das gravações. Inicialmente, os comentários e as respostas dos informantes foram inseridos dos informantes em planilhas do Excel $^{\circledR}$ para posterior armazenamento no banco de dados informatizado do SGVClin ${ }^{\circledR}$ - Software para Geração e Visualização de Cartas Linguísticas (ROMANO; SEABRA; OLIVEIRA, 2014). A partir dos dados inseridos no programa, passou-se à exegese com análises dos relatórios de frequência absoluta e relativa fornecidos pelo software, bem como à configuração das cartas linguísticas das quais se selecionaram três modelos: (i) diatópica com produtividade por ponto linguístico; (ii) arealidade e (iii) arealidade gradual com vistas a discutir os resultados considerando-se o objetivo do presente estudo.

\section{Discussão dos resultados}

Apresentam-se os dados em duas partes: (3.1) a distribuição diatópica das variantes e (3.2) a consciência da variação diatópica revelada pelos comentários dos informantes.

\footnotetext{
${ }^{5}$ Para acesso aos detalhes da rede de pontos, acesse:< https://alib.ufba.br/content/rede-de-pontos > Nesta oportunidade utilizam-se os dados dos informantes de nível fundamental, ou seja, nas capitais, não foram considerados os informantes de nível superior, dados os objetivos do estudo.
} 


\subsection{Mandioca e aipim: perspectiva diatópica}

A questão 50, no corpus analisado, apresenta um total de 341 registros e sete abstenções de resposta. Nas abstenções, consideram-se sob o rótulo "não resposta" duas particularidades: (i) quando o informante declarou desconhecer o designativo para o referente: um único caso, inquérito 192/2 - Macaé/RJ e (ii) quando, ao ouvir as entrevistas, identificou-se algum problema de natureza técnica seja porque a pergunta não foi formulada seja porque não foi gravada a resposta do/a informante por ruído, falha no gravador, nos seguintes casos: 127/4 (Januária-MG); 129/3 (Pedra Azul-MG); 131/3 (Montes Claros-MG); 142/3 (Ouro Preto-MG); 198/2 (Macaé-RJ); 199/2 (Valença-RJ).

Nos demais dados, observa-se a presença de sete variantes lexicais, conforme a distribuição de produtividade em números absolutos e relativos da Tabela 1, computando, inclusive, a "não resposta":

Tabela 1 - Produtividade dos itens na região Sudeste

\begin{tabular}{lll}
\hline Variantes & $\mathbf{N}^{\mathbf{0}}$ & \% \\
\hline Mandioca & 270 & 77.59 \\
Aipim & 64 & 18.39 \\
Macaxeira & 2 & 0.57 \\
Mandioca amarela & 2 & 0.57 \\
Mandioca vassourinha & 1 & 0.29 \\
Mandioca cacau & 1 & 0.29 \\
Mandioca pão & 1 & 0.29 \\
Não resposta & 7 & 2.01 \\
TOTAL & 348 & 100 \\
\hline
\end{tabular}

Fonte: Banco de dados do Projeto ALiB - Relatório SGVCLin ${ }^{\circledR}$

A forma majoritária é a variante mandioca, com 270 registros, seguida da forma aipim, com 64 ocorrências. As denominações pouco produtiva mandioca amarela, vassourinha, cacau e pão foram elicitadas como segunda resposta. Os informantes que as forneceram registraram o item mandioca como primeira resposta e em seguida 
auferiram as características da casca, por exemplo, conforme relatos dos informantes transcritos ipsis litteris ${ }^{6}$ :

INF.- Mandioca.

INQ.- Você já ouviu outro nome?

INF.- Não... tem mandioca cacau, né, que é uma mais vermelha, né, que a casca é bem mais vermelha. Então tem mandioca comum e mandioca cacau. Geralmente tem dois tipo, a... mandioca comum ela é... branca, a casca é quase branca também, né, não é vermelhinha igual quando cê corta, cê vê o vermelho assim. A mandioca cacau já é vermelha. - (Ponto 138/1, Belo Horizonte/MG)

INF.- Mandioca.

INQ.- Tem outros nomes?

INF.- Tem assim a mandioca pão, a mandioca amarela e a mandioca brava.

INQ.- Qual que é a diferença?

INF.- Ah, a mandioca pão eu nunca comi, só que eles fala que quando cunzinha ela, quando discasca pra cunzinhá ela fica cum gosto de pão. Agora brava é pra fazê farinha, né. Agora a mandioca amarela e tem a branca também.

INQ.- A melhor pra comer é qual?

INF.- Amarela. ${ }^{7}$ - (Ponto 169/1, Assis/SP)

INF.- Mandioca.

INQ.- Você conhece um tipo só de mandioca ou mais que um?

INF.- Eu conheço uma branca... uma mandioca, até a casquinha dela é meio branca, que foi... que a mãe trouxe lá do Paraná, da casa da minha irmã lá de Curitiba, e... e vassorinha que eles falam. Uma ota vassorinha.

INQ.- Como que é essa?

INF.- Essa ela é... a casca dela é bem avermelhada assim, meio grossa.

- (Ponto 182/2, Capão Bonito/SP)

Quanto à variante macaxeira, que também foi pouco produtiva como resposta válida entre os informantes, observa-se que ela apresenta apenas duas ocorrências (162/2 e 3 - Adamantina/SP), como forma legítima para uso na localidade para esses informantes.

\footnotetext{
${ }^{6}$ Transcrição grafemática segundo as normas do Projeto ALiB. As siglas INQ. e INF. indicam inquiridor e informante, respectivamente. Trechos sublinhados são sobreposição de vozes.

${ }^{7}$ Vale mencionar que "mandioca brava" é o designativo caput da questão 51, não é abordada nesta oportunidade, dados os objetivos e os limites deste texto.
} 
Quanto à distribuição diatópica dos itens por estado, agrupando-se as formas poucos produtivas no item outras (mandioca vassourinha, mandioca amarela, mandioca pão, mandioca cacau e macaxeira), a Figura 1 apresenta a seguinte situação:

\section{Figura 1 - Produtividade das variantes para a questão 50 do QSL por Unidade Federativa da} Região Sudeste

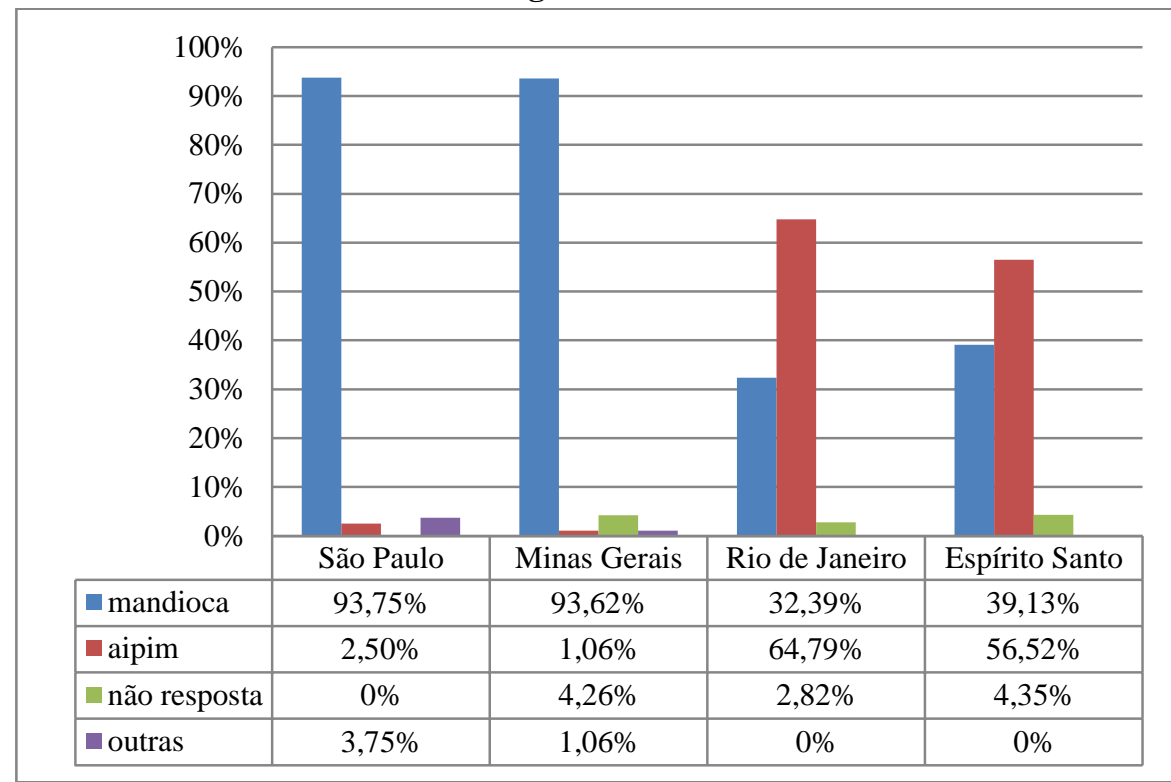

Fonte: Banco de dados do Projeto ALiB - Relatório do SGVCLin ${ }^{\circledR}$

Observam-se dois cenários distintos: a presença predominante do item mandioca nas localidades paulistas e mineiras com quase nenhuma concorrência de aipim; ao passo que, no Rio de Janeiro e no Espírito Santo, esta variante predomina em ambos os estados com liderança, sobretudo, nas localidades fluminenses com $64.79 \%$ de representatividade e 56,52\%, respectivamente. Nesses estados, contudo, o item aipim concorre com mandioca em $32.39 \%$ das respostas dos fluminenses e $39.13 \%$, dos capixabas.

Ainda considerando a distribuição diatópica, são apresentadas quatro cartas linguísticas: (i) uma com a distribuição diatópica dos itens por ponto linguístico; (ii) uma de arealidade gradual para o item mandioca; (iii) uma de arealidade gradual para o item aipim e (iv) a carta de arealidade com iso e heteroléxicas para mandioca e aipim.

Observa-se na Figura 2 a predominância de mandioca (vermelho) em grande parte do território, sobretudo, em MG e em SP; ao passo que há a predominância do item aipim no RJ e ES (cor azul), o que evidencia linhas de isoléxicas representadas pelas cartas de arealidade (Figuras 3 e 4 ). 
A “não resposta" (amarelo) não se encontra nas localidades paulistas e está em duas cidades fluminenses (198 - Macaé e 199 - Valença), em uma localidade capixaba (192 - Alegre) e em quatro pontos de MG (127 - Januária, 129 - Pedra Azul, 131 Montes Claros e 142 - Ouro Preto). As variantes pouco produtivas agrupadas (cor preta) estão em quatro cidades paulistas (162 - Adamantina, 169 - Assis, 182 - Capão Bonito e 183 - Itanhaém). Há um registro também de formas menos produtivas em Belo Horizonte (ponto 138), mandioca cacau.

Figura 2 - Carta linguística com as designações para a questão 50 do QSL em cada ponto

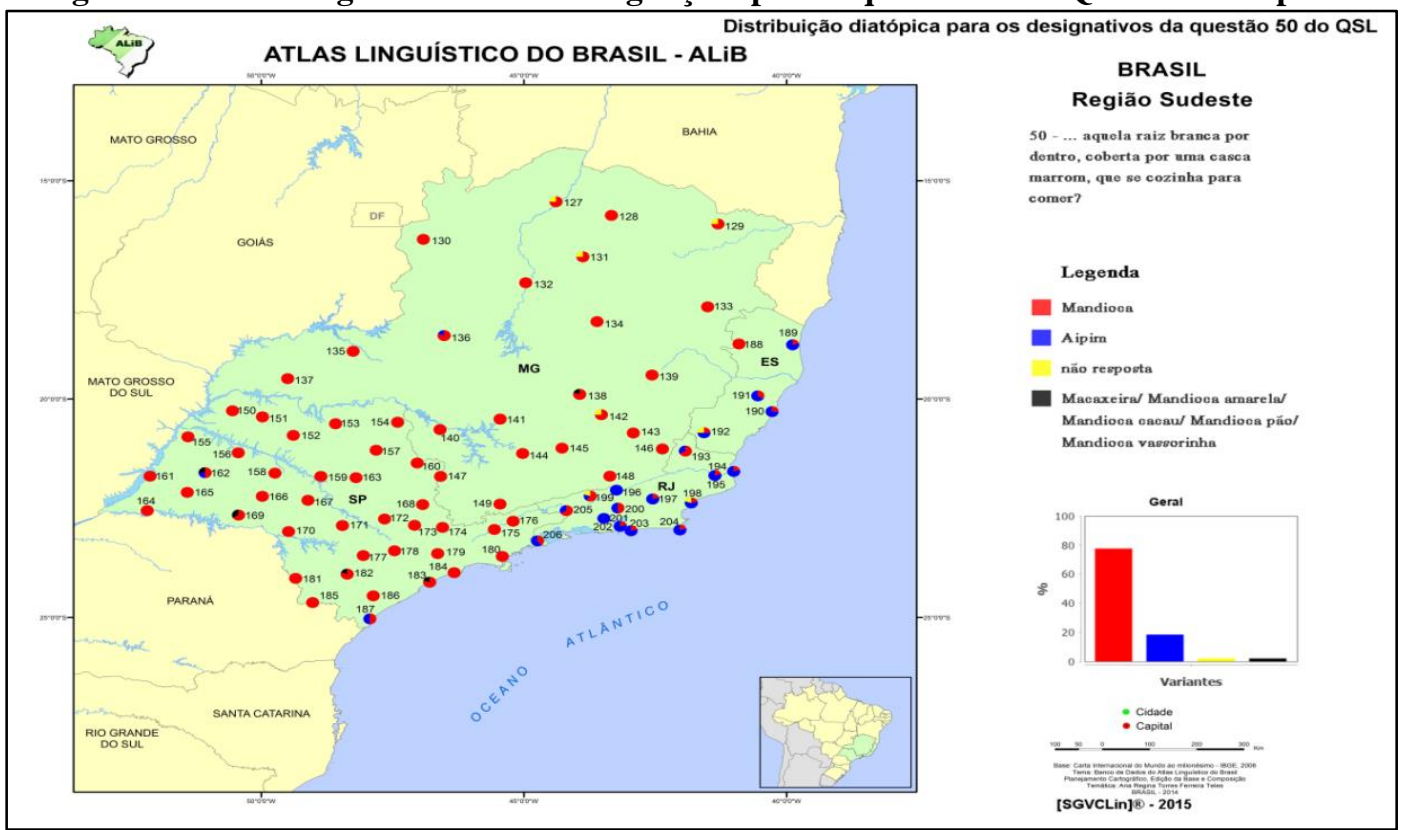

Fonte: Banco de dados do Projeto ALiB - SGVCLin ${ }^{\circledR}$

Figura 3 - Carta de arealidade gradual de mandioca para a questão 50 do QSL na Região Sudeste

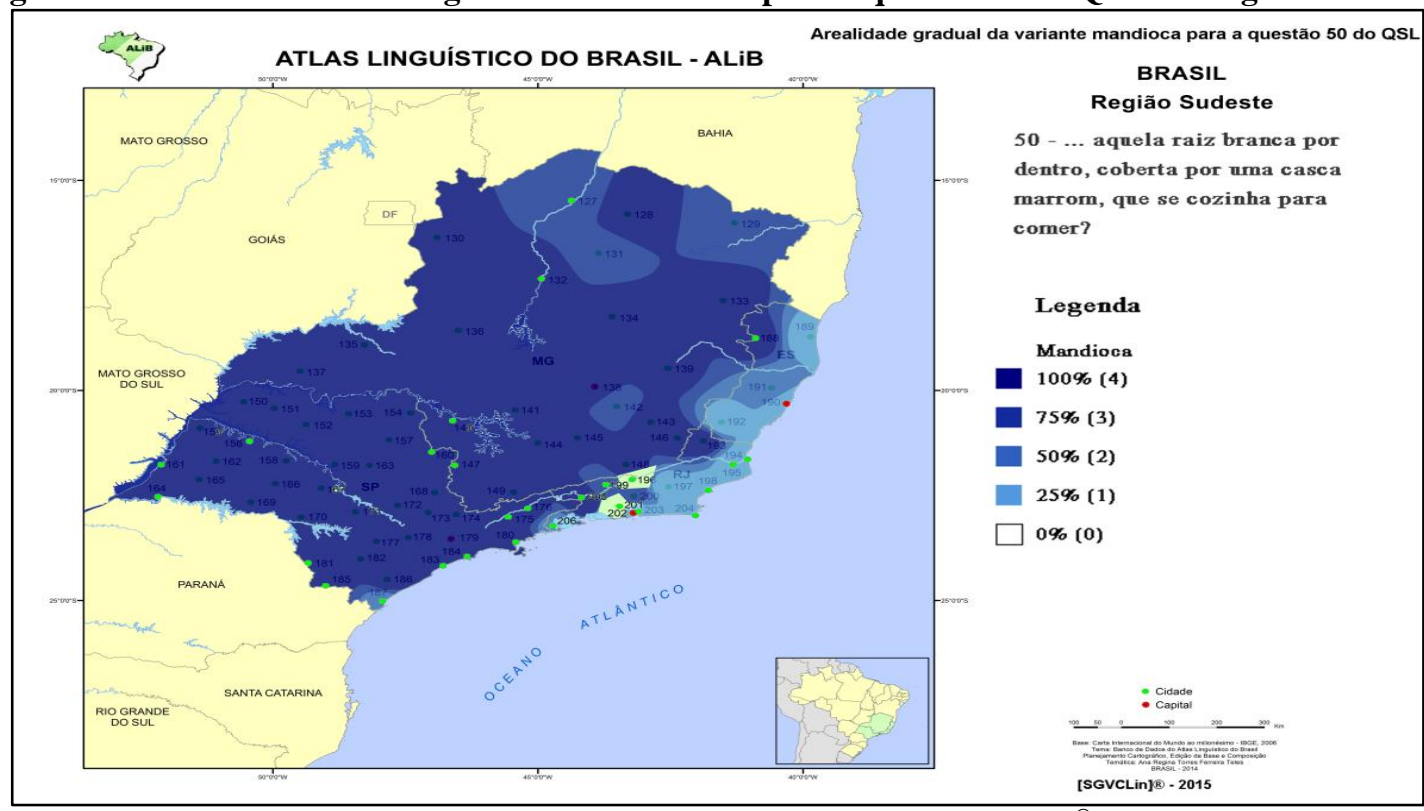

Fonte: Banco de dados do Projeto ALiB - SGVCLin ${ }^{\circledR}$ 
Figura 4 - Carta de arealidade gradual de aipim para a questão 50 do QSL na Região Sudeste

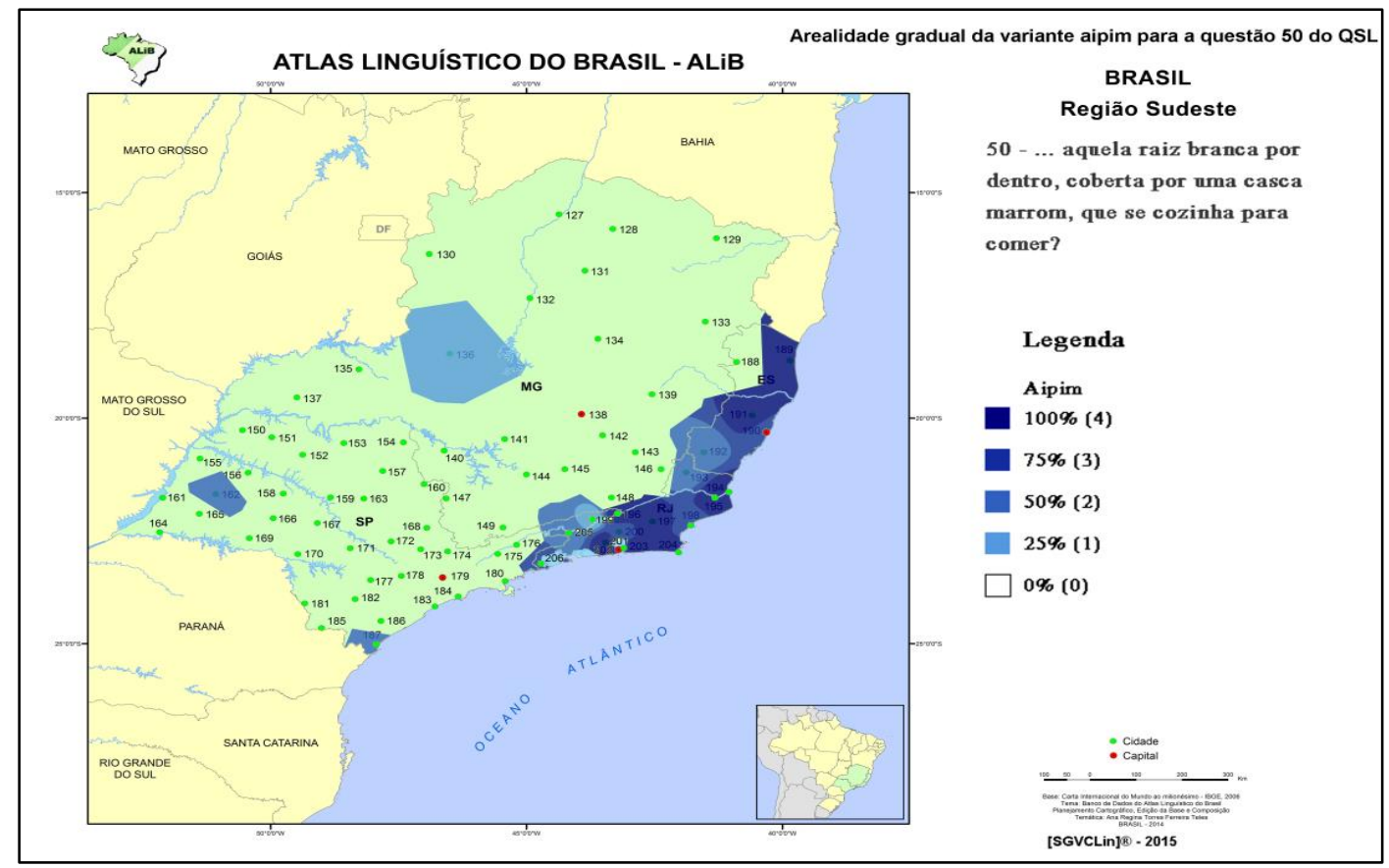

Fonte: Banco de dados do Projeto ALiB - SGVCLin ${ }^{\circledR}$

A Figura 3 traz a distribuição do item mandioca. A ocorrência do item apenas não foi registrada em dois pontos fluminenses, 201 - Nova Iguaçu e 196 - Três Rios. No território paulista, mandioca obteve $100 \%$ de produtividade em quase todos os pontos linguísticos, exceto no extremo sul do litoral (ponto 187 - Cananeia), cuja produtividade atinge $50 \%$ de incidência na fala dos informantes dessa localidade. Observa-se uma maior incidência de mandioca como forma legítima da região, principalmente, em MG e SP, mas também com incidência, mesmo que fraca, no território fluminense e capixaba onde o item ocorre com baixa produtividade, $25 \%$ (uma ocorrência) na maioria dos pontos.

Esse panorama é ratificado pela presença de aipim (Figura 4) nessa área da Região Sudeste, onde a incidência do item atinge 100\% de produtividade no RJ e ES. Em ambas as cartas, é possível observar a delimitação de uma linha de isoléxica que divide o território. Essa linha segue a divisão política que separa MG do ES e RJ, e este com SP; porém com gradiências intermediárias, podendo, inclusive, haver áreas de heteroléxicas de coocorrência dos itens mandioca/aipim, conforme a Figura 5.

Considerando a rede de pontos do ALiB, o SGVCLin ${ }^{\circledR}$, neste tipo de carta, estabelece um interponto e traça a distribuição poligonal dos itens em foco, no caso 
mandioca e aipim. As áreas em vermelho, com hachura horizontal, revelam uma linha isoléxica de mandioca que faz fronteira com a heteroléxica aipim/mandioca (hachura pontilhada em verde) entre MG e os estados do ES e RJ, indicando a projeção de incidência dos itens no território.

Figura 5 - Cartas de iso- e heteroléxica de aipim e mandioca na Região Sudeste

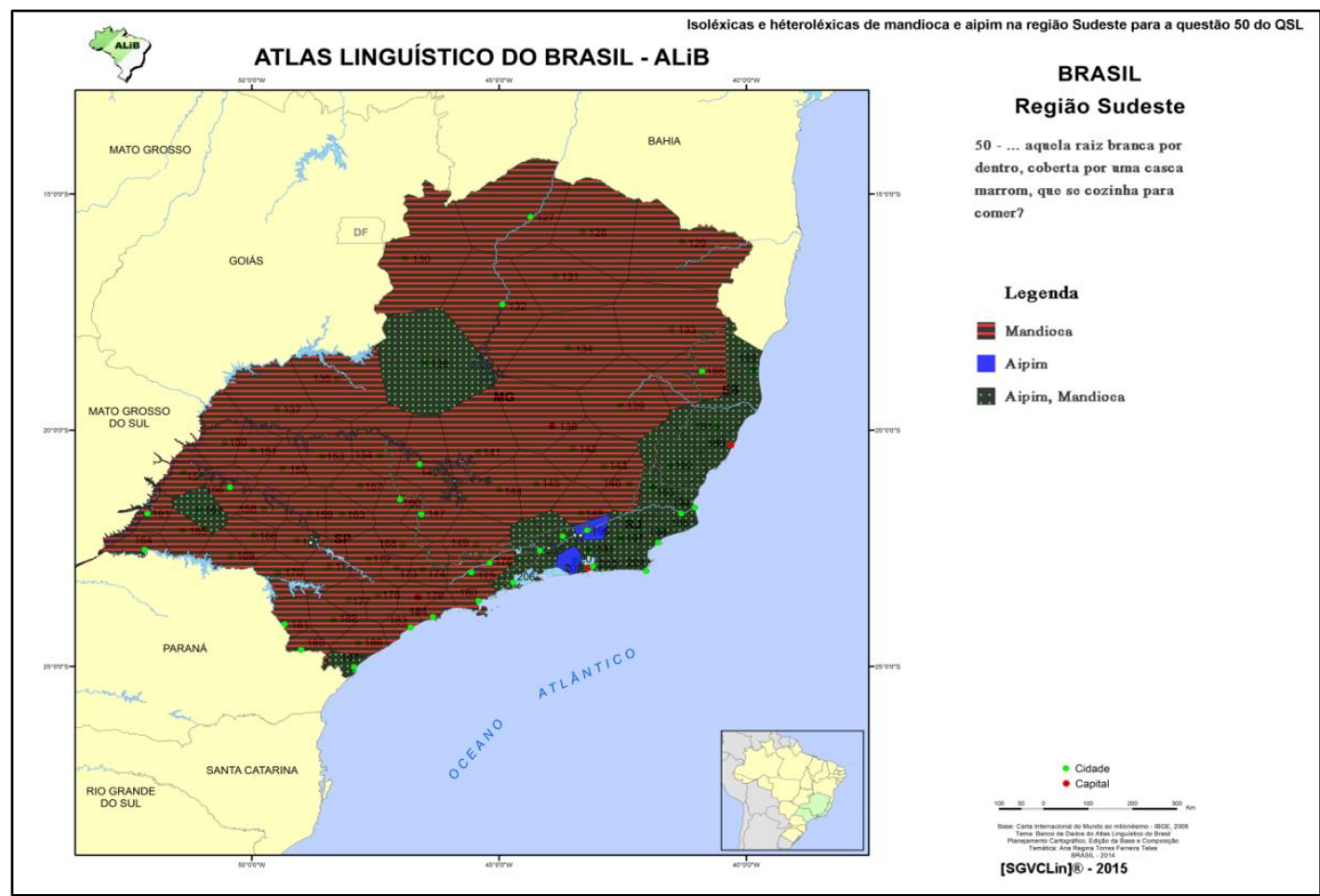

Fonte: Banco de dados do Projeto ALiB - SGVCLin ${ }^{\circledR}$

Há também três outras áreas em que ambos os itens ocorrem, ponto 136 (Patos de Minas), no oeste de MG, ponto 162 (no oeste paulista - Adamantina) e 187 (litoral sul paulista - Cananeia). Na Região Sudeste, os únicos pontos com ocorrência exclusiva de aipim foram: 201 - Nova Iguaçu (RJ) e 196 - Três Rios (RJ). Observe-se, desse modo, certa homogeneidade linguística entre os estados de SP e MG, com mandioca e ES e RJ, com aipim mais produtivamente, mas também com ocorrência da variante mandioca.

Talvez a presença de aipim no extremo sul do litoral paulista possa dar indícios do ponto final/inicial de outra área lexical no território brasileiro à medida que se adentra em direção à Região Sul do país, uma vez que a carta L08 do ALiB (CARDOSO et al. 2014b) documenta a presença do item em Curitiba, onde concorre 
com mandioca, porém de forma mais produtiva (aipim 68.1\%) e a ocorrência exclusiva de aipim nos dados de Florianópolis e Porto Alegre ${ }^{8}$.

\subsection{Comentários diatópicos dos informantes}

Mandioca e aipim são as duas principais variantes na Região Sudeste do país e indicam áreas lexicais de acordo com o uso dos informantes. Nos dados quantificados, foram consideradas apenas as formas validadas por eles como pertencentes ao léxico usual na localidade. Porém, esse cenário se amplia quando se consideram os comentários dos entrevistados, revelando a consciência da variação diatópica nos designativos para o referente perguntado. Quando indagados sobre o uso da forma aipim ou macaxeira, por exemplo, foram diversos os comentários dos informantes que asseveram tratar-se de formas comuns a outros estados/regiões ou grupos de forma genérica.

Quanto ao item macaxeira, selecionaram-se algumas observações dos informantes como as que seguem:

INQ.- Quem fala macaxera?

INF.- Ah, outras pessoas, né, que vem visitar, às vez e pergunta, né. Às veiz, lá em casa eu já tive um pessoal da... que veio um pessoal baiano, aí a gente tava fazendo um bolim (=bolinho), e ele falou quero um bolim de macaxera, macaxera, aí eu achei interessante assim, mas não que lá na Bahia eles falam assim, não. Lá é de outro nome, só que ele veio de um outro lugar e tava falando assim com a gente lá, e como eu não entendia, ele explicô e eu contei pra ele que a gente chamava como mandioca mesmo, né, porque ele, pai dele mexe com coisas da igreja então eles moram fora assim, então eles vão pegando o custume às vezes, então cada lugar é um nome que eles pegam.(Ponto 144 - Lavras/MG )

INQ.- Onde você ouviu macaxera?.

INF.- Às vezes pela televisão e vem muito nortista trabalhá aqui em Poços de Calda, tem muito nortista que veio, então pessoal costuma falá. (Ponto 147 - Poços de Caldas/MG)

INF.- Uns fala mandioca, otos fala macaxera. Nortista fala macaxera, e nóis paulista é mandioca. A rama de man... é na mandioca. A rama é o pé, né, agora a raiz é a mandioca. Mai o nortista fala macaxera.

INQ.- Aqui fala mais mandioca?

INF.- É, aqui nói fai mais mandioca. "Ah, fazê a farinha de mandioca, vamo fazê a mandioca cuzida, vamo cuzinhá a mandioca, e fazê churrasco". É só a mandioca que rola. O nome dela. (Ponto 155 - Andradina/SP)

\footnotetext{
${ }^{8} \mathrm{O}$ trabalho com corpus do interior na Região Sul, assim como nas outras regiões administrativas (Centro-Oeste, Nordeste e Norte) está em fase de revisão e levantamento. Os dados para as questões 50 e 51 , referentes ao interior do país, estão previstos para serem apresentados na cartografia do vol. 6 e 7 do ALiB (em elaboração).
} 


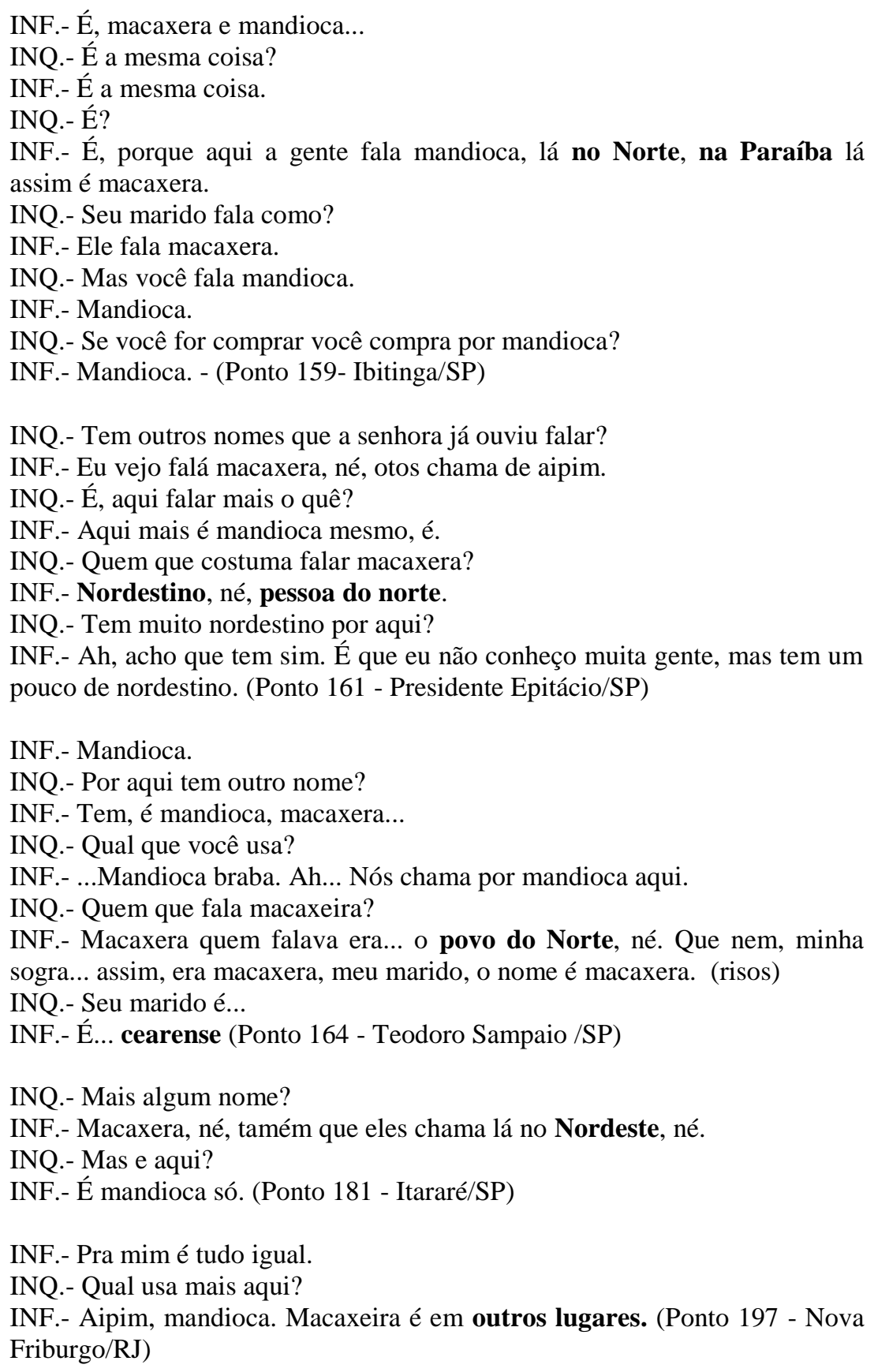

Apesar de macaxeira ocorrer como resposta válida para quantificação e cartografia apenas em uma localidade, sendo atestada pelos informantes 2 e 3 de Adamantina, no oeste de SP, como forma usual para esses dois informantes, há a presença desse item em comentários dos informantes em pelo menos 10 pontos linguísticos, sobretudo, entre os paulistas. Dos excertos selecionados, tem-se observado a referência direta que se faz ao uso de macaxeira em relação à variação diatópica, relacionada às regiões Norte e Nordeste, seja pelo contato que se tem com as pessoas de outras regiões (migrantes): 147/1 (Poços de Caldas/MG), 161/4 (Presidente 
Epitácio/SP), 164/4 (Teodoro Sampaio/SP) ou pelos meios de comunicação como a televisão (147/1 - Poços de Caldas/MG).

É interessante observar que no estado de SP essa forma ocorreu, principalmente, na região oeste (Adamantina/SP, como resposta válida; e em comentários de informantes de Presidente Epitácio, Andradina e Teodoro Sampaio), área paulista que recebeu grande contingente migratório de nordestinos na década de 1940, a partir de iniciativas governamentais, cujas influências linguísticas encontram-se documentadas no ATOSP - Atlas Linguístico Topodinâmico do Oeste de São Paulo (SANTOSIKEUCHI, 2014), por exemplo9.

A carta 23 (Figura 6) do referido atlas traz a distribuição das variantes para o referente da questão 50 do QSL do ALiB, na fala de informantes de nível básico de escolaridade (cruz superior) e universitário (cruz inferior) de duas faixas etárias, em quatro cidades do oeste paulista (Andradina - ponto 1, Adamantina - ponto 2, Rancharia - ponto 3 e Presidente Epitácio, ponto 4):

Figura 6 - Carta linguística 23 do ATOSP

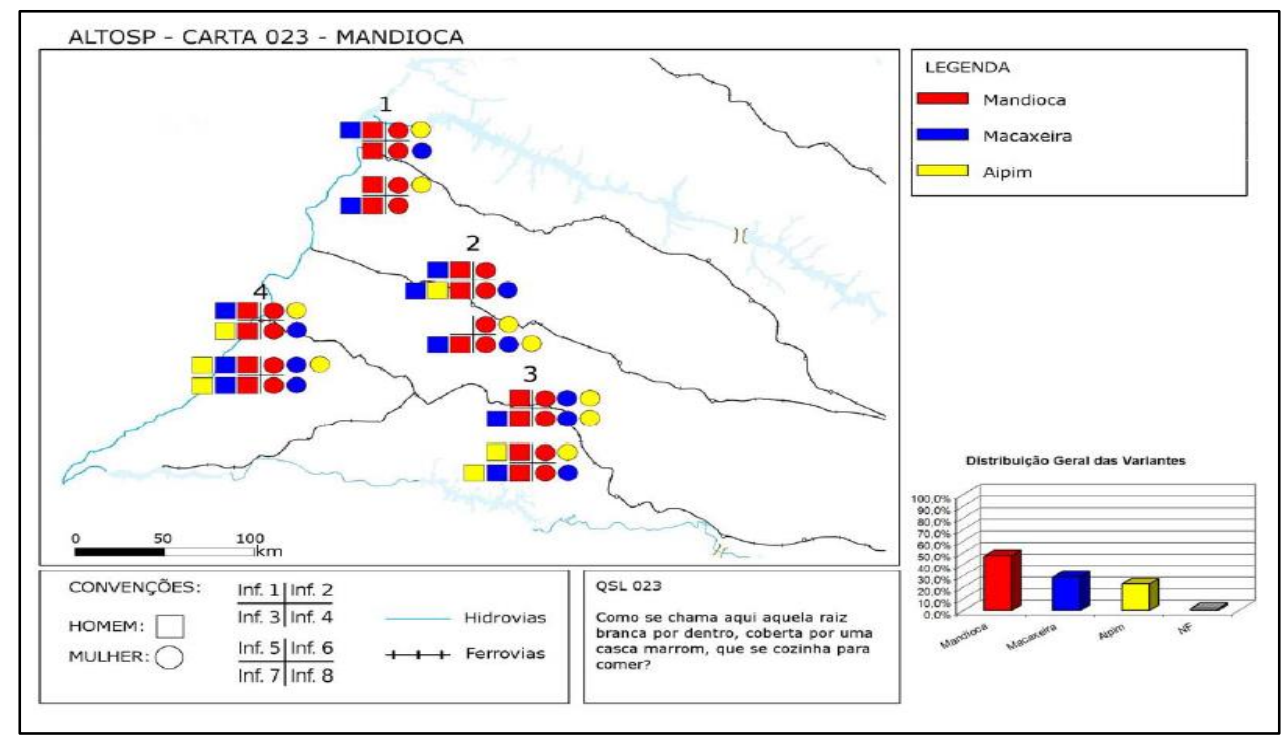

Fonte: Santos-Ikeuchi (2014)

A variante macaxeira ocorre como segunda ou terceira resposta dos informantes de perfil topodinâmico (migrantes/filhos de migrantes nordestinos) do ATOSP (SANTOS-IKEUCHI, 2014) e também de forma inconteste em outros atlas de pequeno

\footnotetext{
${ }^{9}$ A dimensão diatópica da variação linguística, segundo a Dialetologia Pluridimensional (THUN, 1998), pode der observada a partir de dois parâmetros: (i) com informantes de perfil topodinâmico (informantes migrantes de outras áreas) ou com informantes de perfil topoestático (naturais da localidade ou região linguística, com nenhuma ou pouca mobilidade). Um exemplo de atlas linguístico topodinâmico e topoestático no Brasil é o do estado de Tocantins elaborado por Silva (2018).
}

Revista Moara, n. 55, jan-jul 2020 ISSN: 0104-0944

Recebido em 23/03/2020

Avaliado em 12/06/2020 
domínio da Região Nordeste, porém com informantes topoestáticos (naturais da localidade), como se observa na carta 40 do Atlas Linguístico de Icatu/MA (MENDONÇA, 2017), na carta 19 do Atlas Linguístico do Centro-Oeste Potiguar/RN (SILVA, 2012) e na carta 13 do Atlas Linguístico da Mata Sul de Pernambuco/PE (ALMEIDA, 2009), para citar apenas três atlas nordestinos de pequeno domínio.

Entre os atlas estaduais, mencionam-se a carta 57 do Atlas Linguístico do Estado de Alagoas (BARBOSA-DOIRON, 2017) e a carta L12 do Atlas Linguístico do Amapá (RAZKY; RIBEIRO, SANCHES, 2017) que também trazem a presença inconteste de macaxeira com alta produtividade em todos os pontos linguísticos de cada um desses dois atlas mencionados. Além do mais, a carta L08 do ALiB (CARDOSO et al., 2014b) apresenta o item macaxeira como forma predominante em todas as capitais da Região Norte e em oito das nove capitais nordestinas com alto percentual de produtividade, chegando a 100\% de ocorrência em São Luís e Recife, e em Macapá, Boa Vista, Manaus e Rio Branco, entre as capitais nortistas. Ou seja, macaxeira é uma forma legítima para denominar o referente que, na região Sudeste, conhece-se como mandioca, e os informantes, sobretudo, paulistas, reconhecem essa legitimidade.

Já quanto à variante aipim, também os informantes forneceram comentários diatópicos, porém de forma mais genérica, por vezes, equivocada:

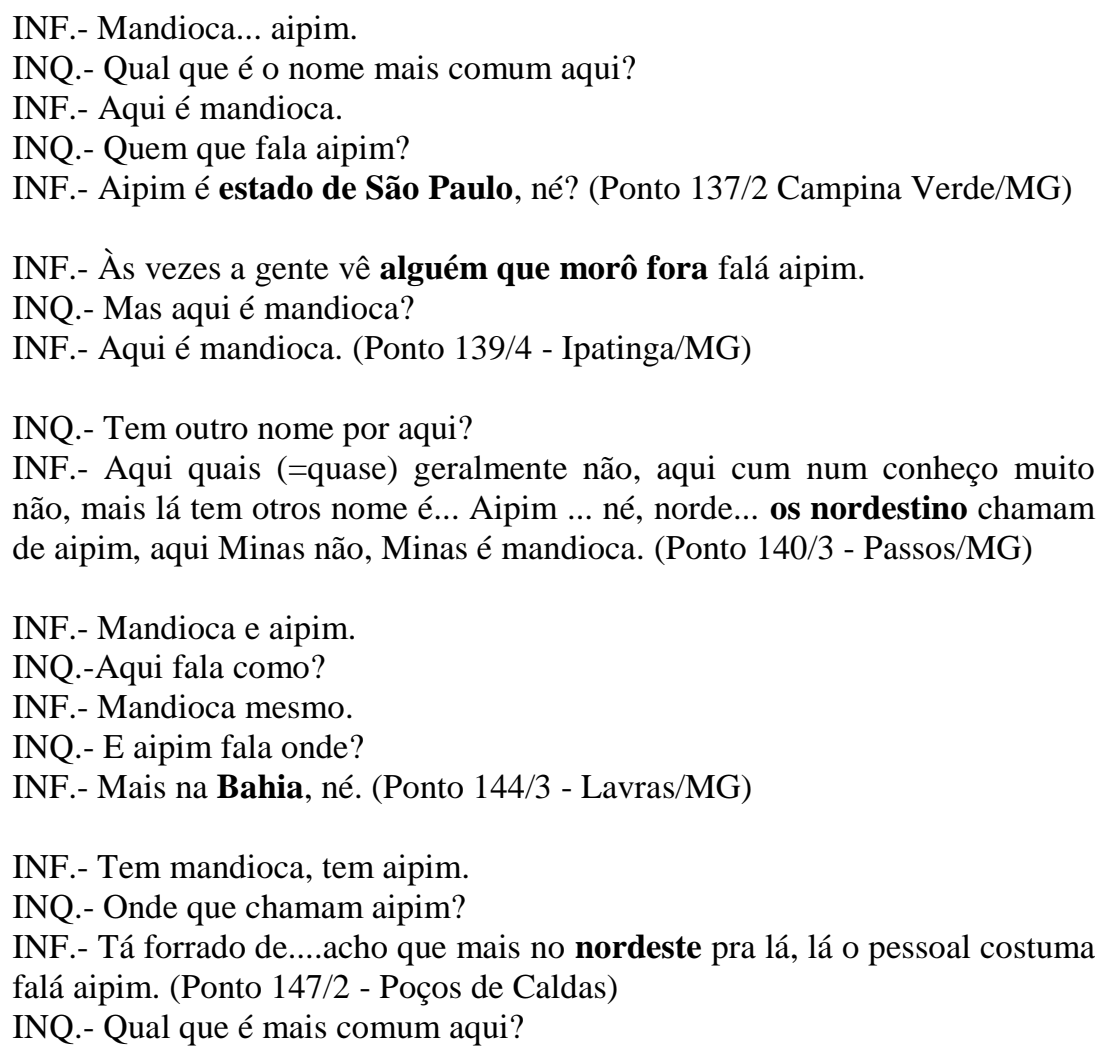


INF.- A gente, pra gente aqui é... se torna mais a mandioca, né. Agora as pessoas nordes... nordestina que fala mai aipim. (Ponto 184/2 - Santos/SP).

INQ.- É a mesma coisa?

INF.- É, aqui a gente fala mandioca, tem uns que fala aipim, la pro lado de Minas, não sei. (Ponto 205/1 - Barra Mansa/RJ)

Observa-se pelos trechos selecionados que há informantes que genericamente relacionam o uso da variante aipim à região Nordeste ou até mesmo à fala de paulistas e mineiros. Por outro lado, há comentários que mencionam o uso à fala de cariocas, que são ratificados pelos dados do presente artigo, conforme as cartas linguísticas apresentadas e os comentários:

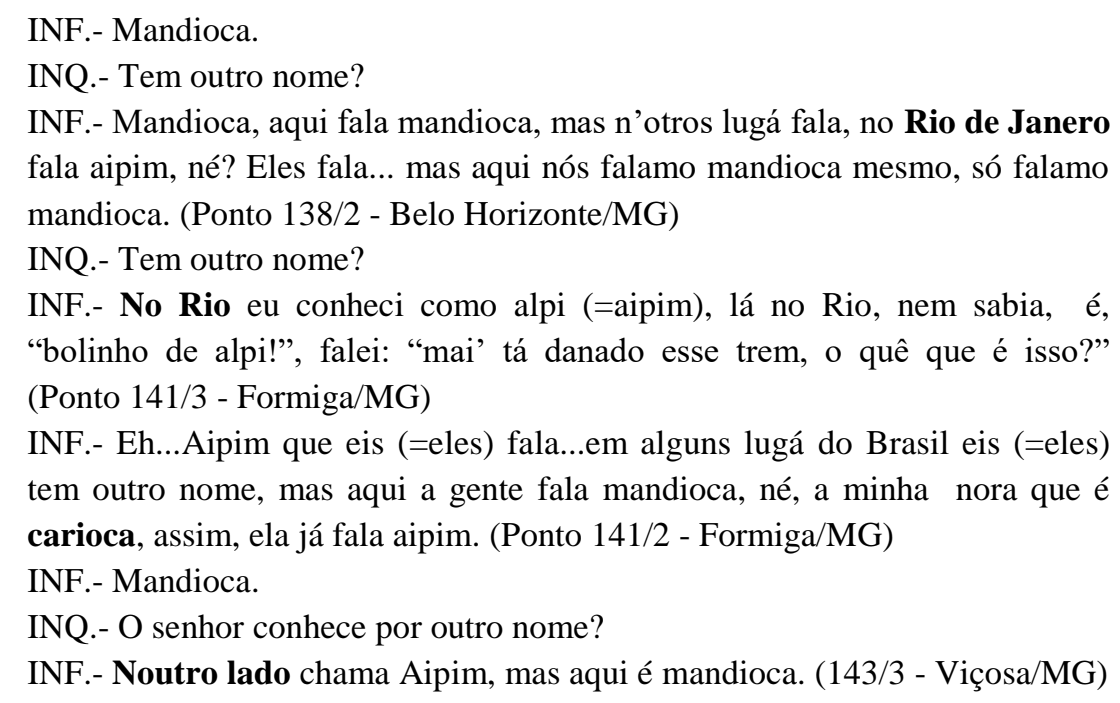

Nesse último trecho, o informante mencionou "noutro lado" para se referir ao estado do RJ, uma vez que Viçosa se encontra próxima à fronteira política de MG com o território fluminense. Ou seja, pelo que se observa, mesmo que não fazendo parte do seu léxico ativo, os informantes conhecem formas diferentes para denominar o referente, revelando a consciência de variação diatópica na denominação desse tubérculo, embora o faça por vezes de forma generalizada.

\section{Considerações Finais}

Com este estudo foi possível verificar a presença de duas áreas linguísticas na Região Sudeste que apresentam certa homogeneidade no que se refere ao léxico. Uma área que engloba os estados de SP e MG, com presença do item mandioca e outra com a 
predominância de aipim no RJ e no ES. Foi possível verificar essas áreas, visualmente, devido aos tipos de mapas escolhidos para a representação: os de arealidade, tanto os que trazem a gradiência das ocorrências por meio de contínuos entre as formas documentadas, quanto os mapas poligonais de arealidade com hachuras. Esse particular, possivelmente, será considerado na cartografia dos volumes futuros do Atlas Linguístico do Brasil, ocasião em que serão apresentados nos mapas linguísticos os dados da rede de pontos do interior do país. Uma cartografia por estados não revelaria esses contínuos, por exemplo. Portanto, o estudo suscita reflexões.

Por se tratar de um referente comum no cotidiano do brasileiro e de fato ser um item da culinária que revela nitidamente a variação diatópica do $\mathrm{PB}$, observa-se que a consciência da variação por parte das pessoas está de acordo com o que se desenvolve em termos de pesquisa acadêmica, mas que, em alguns casos, apresenta-se na fala dos brasileiros de forma genérica e estereotipada para identificar grupos/regiões. Nesse sentido, os atlas linguísticos, sobremaneira o $\mathrm{ALiB}$, contribuem para o enriquecimento cultural, linguístico e identitário do PB e das regiões brasileiras. O desafio lançado está em possibilitar ao cidadão comum, leigo no assunto, o acesso aos atlas de forma facilitada para desconstrução de preconceitos e estereótipos que se tem do modo de como se fala e do modo de como o outro se expressa. A diversidade é imanente e isso o brasileiro reconhece.

Por fim, mas não menos importante, este estudo não encerra a discussão acerca dos designativos, uma vez que é uma pesquisa em andamento com dados de todo o país e envolve, inclusive, a questão 51 do QSL (mandioca brava), complementar à questão 50 (mandioca mansa). Nos limites do texto, não foram trazidos os aspectos etimológicos das variantes e os traços de brasilidade desse alimento, cujo cultivo/uso remonta tempos anteriores à chegada dos portugueses em terras brasileiras. Envolta a mitos e lendas, essa raiz tipicamente brasileira, base econômica de algumas cidades/regiões, revela traços da influência tupi-guarani na constituição do PB. Mas esse é assunto para outro texto. 


\section{REFERÊNCIAS}

AGUILERA, V. de A. Atlas Lingüístico do Paraná. Curitiba: Imprensa Oficial, 1994.

AGUILERA, V. de A. Crenças e atitudes lingüísticas: quem fala a língua brasileira? In: RONCARATI, C.; ABRAÇADO, J. (Orgs.). Português brasileiro II: contato lingǘrtico, heterogeneidade e história. Niterói: Ed. da UFF, 2008. p.311-333

AlMeIDA, E. M. O de. Atlas Linguístico da Mata Sul de Pernambuco. 2009. 351 p. Dissertação (Metrado em Letras), Universidade Federal da Paraíba, João Pessoa, 2009.

ARAGÃO, M. do S.; MENEZES, C. Atlas Lingüístico da Paraíba. 2. v. Brasília: Universidade Federal da Paraíba: CNPq, 1984.

BARBOSA-DOIRON, M. Motivação semântica nas respostas do Atlas Linguístico do Estado de Alagoas - ALEAL. 2017. 2 v.. Tese (Doutorado em Estudos da Linguagem), Universidade Estadual de Londrina, Université Greboble Alpes, Londrina/Grenoble, 2017.

BIDERMAN, M. T. C. Léxico, testemunho de uma cultura. XIX CONGRESO INTERNACIONAL DE LINGUÍSTICA E FILOXÍA ROMÁNICAS. Actas... A Coruña: Fundación Pedro Barrié de la Maza, Conde de Fenosa, 1992, p. 397-405.

BRASIL. Decreto n. ${ }^{\circ}$ 30.643, de 20 de março de 1952. Institui o Centro de Pesquisas da Casa de Rui Barbosa e dispõe sobre seu funcionamento. Diário Oficial da União, Brasília, 20 mar. 1952.

CARDOSO, S. A. M. S. et al. Atlas Linguístico do Brasil - Vol. 1 (Introdução). Londrina: EDUEL, 2014a.

CARDOSO, S. A. M. S. et al. Atlas Linguístico do Brasil - Vol. 2 (cartas Linguísticas). Londrina: EDUEL, $2014 \mathrm{~b}$.

CHOFARD, A. Aspectos lexicais do Português brasileiro: um recorte de variantes documentadas pelo Atlas Linguístico do Brasil. 2019, 247 p. Dissertação (Programa de Pósgraduação em Linguística), Universidade Federal de Santa Catarina, Florianópolis, 2019.

COMITÊ NACIONAL DO PROJETO ALiB. Atlas Lingüístico do Brasil: Questionários 2001. Londrina: Ed. da UEL, 2001.

CUNHA, C. F. da; SILVA NETO, S. da. Atlas Linguístico-Etnográfico do Brasil. In: COLÓQUIO INTERNACIONAL DE ESTUDOS LUSO-BRASILEIROS, 3., 1957, Lisboa. Actas... Lisboa: [S.1], 1960. v. II. p.405-412.

D’ANUNCIAÇÃO, E. S. Registrando o léxico dos brinquedos infantis em Minas Gerais. 2016. 86 f. (Monografia) - Instituto de Letras, Universidade Federal da Bahia, Salvador, 2016.

FERREIRA, C. et al. Atlas Lingüístico de Sergipe. Salvador: Universidade Federal da Bahia: Fundação Estadual de Cultura de Sergipe, 1987.

FREITAG, R. M. K.; SEVERO, C. G; ROST-SChINELOTO, C. A.; TAVARES, M. A. Como o brasileiro acha que fala? Desafios e propostas para a caracterização do "português brasileiro". Signo y seña, Buenos Aires, UBA, n. 28, p. 65-87, 2015.

ISQUERDO, A. N. Designações para estilingue em atlas lingüísticos brasileiros: perspectivas diatópica e sócio-histórica. In.: TROTTER, David (Ed.) XXIVE CONGRÈS INTERNATIONAL DE LINGUISTIQUE ET DE PHILOLOGIE ROMANES. Actes... Tome I. Tübingen: Max Niemeyer Verlag, 2007. p. 533-546. 
LUCCHESI, D. Parâmetros Sociolinguísticos do Português Brasileiro. Revista da ABRALIN, v. 5, n.1. dez., p.83-112, 2006,.

MARINS, L. G. F. O rural e o urbano: novos e velhos falares na região Centro-Oeste do Brasil. 2012, 307 F. Dissertação (Mestrado em Estudos de Linguagem), Universidade Federal do Mato Grosso do Sul, Campo Grande, 2012.

MENDONÇA, T. A. Atlas Linguístico de Icatu. 2017, 389 p. Dissertação (Metrado em Letras), Universidade Federal do Maranhão, São Luis, 2017.

NASCENTES, A. O linguajar carioca. 2. Ed. Rio de Janeiro: Organização Simões, 1953.

NASCENTES, A. Bases para a elaboração do Atlas Lingüístico do Brasil. Rio de Janeiro: MEC: Casa de Rui Barbosa, 1958. v. I.

PORTILHO, D. A. S. O falar amazônico: uma análise da proposta de Nascentes (1953) a partir de dados do Projeto ALiB. 2013. 155f. Dissertação (Mestrado em Estudos de Linguagens) Universidade Federal do Mato Grosso do Sul, Campo Grande, 2013.

RAZKY, A. A dimensão sociodialetal do léxico no Projeto Atlas Linguístico do Brasil. Signum: Estudos da Linguagem, Londrina, UEL, v. 13, n. 2, p. 247-270, 2013.

RAZKY, A; RIBEIRO, C. M. da R.; SANCHES, R. Atlas Linguístico do Amapá. São Paulo: Labrador, 2017.

RIBEIRO, S. S. C. Brinquedos e brincadeiras infantis na área do falar baiano. 2012, 466 p. Tese de Doutorado (Programa de Pós-graduação em Letras e Linguística). Universidade Federal de Bahia, Salvador, 2012.

RIBEIRO, J. et al. Esboço de um atlas linguístico de Minas Gerais. Rio de Janeiro: Casa de Rui Barbosa, 1977.

ROMANO, V. P. Balanço crítico da Geolinguística brasileira e a proposição de uma divisão. Entretextos, Londrina, UEL, v. 13, n.2, jul.- dez., p. 203-242, 2013.

ROMANO, V. P. Em busca de falares a partir de áreas lexicais no centro sul do Brasil. 2015. v.1: 286f.; v. 2: 117f. Tese (Doutorado em Estudos da Linguagem) - Universidade Estadual de Londrina, Londrina, 2015.

ROMANO, V. P. Desdobramentos, desafios e perspectivas da Geolinguística Pluridimensional no Brasil. In.: MOTA, J.; OLIVEIRA, J. PAIM, M. RIBEIRO, S. (orgs.). Contribuições de estudos geolinguísticos para o português brasileiro: uma homenagem a Suzana Cardoso. Salvador: EDUFBA (no prelo).

ROMANO, V. P.; AGUILERA, V. de A. Padrões de variação lexical no sul do Brasil a partir dos dados do Projeto ALiB. Estudos Linguísticos, São Paulo, v. 43, n. 1, p. 575-587, 2014.

ROMANO, V. P.; SEABRA, R. D. Dados geolinguísticos sob uma perspectiva estatística: a variação lexical no Centro-Oeste, Sudeste e Sul do Brasil. Revista de Estudos da Linguagem, Belo Horizonte, UFMG, v. 22, n. 2, p. 59-92, 2014a.

ROMANO, V. P.; SEABRA, R. D. Menino, guri ou piá? Um estudo diatópico nas regiões Centro-Oeste, Sudeste e Sul a partir dos dados do Projeto Atlas Linguístico do Brasil. Alfa: Revista de Linguística, São José do Rio Preto, UNESP, v. 58, n. 2, p. 463-497, 2014 b. 
ROMANO, V. P.; SEABRA, R. D. Do presente para o passado: a variação lexical em Minas Gerais a partir de corpora geolinguísticos sobre brinquedos infantis. RELin Revista de Estudos da Linguagem, Belo Horizonte, UFMG, v. 25, n. 1, p. 111-150, 2017.

ROMANO, V. P.; SEABRA, R. D.; OLIVEIRA, N. [SGVCLin] - Software para geração e visualização de cartas linguísticas. RELin Revista de Estudos da Linguagem. Belo Horizonte, UFMG, v. 22, n.1, p. 119-151, 2014.

ROSSI, N.; CALLOU, D.; FERREIRA, C. Atlas prévio dos falares baianos. Rio de Janeiro: Ministério de Educação e Cultura - Instituto Nacional do Livro, 1963

SANTOS, L. A. dos. Brincando pelos caminhos do falar fluminense.2016. 197f. Dissertação (Mestrado em Língua e Cultura) - Universidade Federal da Bahia, Salvador, 2016.

SANTOS-IKEUCHI, A. C. dos. Atlas Linguístico Topodinâmico do Oeste de São Paulo. 2014. 2v. Dissertação (Metrado em Estudos da Linguagem), Universidade Estadual de Londrina, Londrina, 2014.

SILVA, G. A. da. Atlas Linguístico Topodinâmico e Topoestático do Estado do Tocantins (ALITTETO). 2018. 2v. Doutorado (Tese em Estudos da Linguagem), Universidade Estadual de Londrina, Londrina, 2018.

SILVA, M. B. da. Atlas linguístico do centro-oeste Potiguar. 2012. 327f. Tese (Doutorado em Linguística), Universidade Federal do Ceará, Fortaleza, 2012.

THUN, H. Atlas linguistique et variabilité - introduction à la table ronde. In: CONGRÈS INTERNATIONAL DE LINGUISTIQUE ET DE PHILOLOGIE ROMANES, 22., 1998, Bruxelles. Actes... Tübingen: Max Niemeyer, 2000. v. III. p.407-409.

YIDA, V. Normas lexicais no Português Brasileiro: uma descrição de regionalismos nos dados do campo semântico da alimentação e cozinha do Projeto Atlas Linguístico do Brasil. 2019. 2v. Tese (Doutorado em Estudos da Linguagem) - Universidade Estadual de Londrina, Londrina, 2019. 